\title{
Anticancer effects of gallic acid isolated from Indonesian herbal medicine, Phaleria macrocarpa (Scheff.) Boerl, on human cancer cell lines
}

\author{
A. FARIED ${ }^{1,3^{*}}$, D. KURNIA ${ }^{4 *}$, L.S.FARIED ${ }^{2}$, N. USMAN ${ }^{3}$, T. MIYAZAKI ${ }^{1}$, H. KATO $^{1}$ and H. KUWANO ${ }^{1}$ \\ Departments of ${ }^{1}$ General Surgical Science, ${ }^{2}$ Gynecology and Reproductive Medicine, Gunma University, Maebashi, \\ Japan; ${ }^{3}$ Department of Surgery, Padjadjaran University Faculty of Medicine; ${ }^{4}$ Department of Chemistry, \\ Padjadjaran University Faculty of Mathematics and Natural Sciences, Bandung, Indonesia
}

Received September 28, 2006; Accepted November 24, 2006

\begin{abstract}
The natural antioxidant gallic acid (GA) was isolated from fruits of a medicinal Indonesian plant, Phaleria macrocarpa (Scheff.) Boerl. The structure was identified on the basis of spectroscopic analysis and comparison with authentic compound. GA demonstrated a significant inhibition of cell proliferation in a series of cancer cell lines and induced apoptosis in esophageal cancer cells (TE-2) but not in noncancerous cells (CHEK-1). Observation of the molecular mechanism of apoptosis showed that GA up-regulated the proapoptosis protein, Bax, and induced caspase-cascade activity in cancer cells. On the other hand, GA down-regulated antiapoptosis proteins such as Bcl-2 and Xiap. In addition, GA also induced down-regulation of the survival Akt/mTOR pathway. In non-cancerous cells, we observed delayed expression of pro-apoptosis related proteins. Our results suggest that GA might be a potential anticancer compound. However, in depth in vivo studies are needed to elucidate the exact mechanism.
\end{abstract}

\section{Introduction}

The continuing problems caused by malignant disease and the failure of conventional chemotherapy to cure advanced invasive carcinoma indicate that new approaches to control the disease are critically needed. The main concept of chemoprevention has become an important and feasible strategy for cancer treatment. The idea is to control the occurrence of cancer by slowing, blocking or reversing the development of

Correspondence to: Dr Ahmad Faried, Department of General Surgical Science (Surgery I), Gunma University, 3-39-22, Showamachi, Maebashi, Gunma 371-8511, Japan

E-mail: afaried@med.gunma-u.ac.jp

${ }^{*}$ Contributed equally

Key words: Indonesia medicinal plant, Phaleria macrocarpa (Scheff.) Boerl, Mahkota Dewa, gallic acid, human cancer cell lines, apoptosis the disease through the administration of naturally occurring or synthetic compounds (1).

Phaleria macrocarpa (Scheff.) Boerl (Thymelaceae) or Phaleria papuana Warb var. Wichnannii (Val) Back is a popular herbal medicine in Indonesia known as Mahkota Dewa or MaDe. This plant is a dense evergreen tree which was originally found in Irian Jaya, in the eastern part of Indonesia. Its potency as an anticancer agent has been known for generations, and its fruit, seed, and leaf extracts have been widely used by the Indonesian people. In the search for novel biologically active compounds as anticancer agents from Indonesian plants, we studied the active constituents of the fruits of MaDe. Our previous study showed that the crude extract of MaDe fruits indicated pro-apoptosis activity on esophageal cancer cells (Faried A et al, unpublished data). Isolation and purification of the active constituents from $\mathrm{MeOH}$ extract of the fruit of this plant guided by lethality assay against brine shrimp resulted in a known active compound of gallic acid (GA; 3,4,5-trihydroxybenzoic acid), a famous natural antioxidant.

GA is a polyhydroxyphenolic compound which can be found in various natural products, such as green tea, grapes, strawberries, bananas and many other fruits (2). GA was reported as a free radical scavenger and as an inducer of differentiation and apoptosis in leukemia, lung cancer, and colon adenocarcinoma cell lines, as well as in normal lymphocyte cells (3-6). It has been postulated that GA plays an important role in the prevention of malignant transformation and cancer development (7).

Cancer cells reflect the balance between the rates of cell proliferation vs. apoptosis. Mammalian target of rapamycin (mTOR) is the main regulator for life or death signals. Downregulation of the Akt/mTOR survival pathway strengthens the death signals, whereas the up-regulation of this signaling converging on mTOR inhibits the apoptotic program. The synergy between the inhibition of the growth factor and stimulation of the apoptotic pathway might promote the decrease of the anti-apoptosis, Bcl-2 level, enhancing the tumor cell sensitivity to apoptosis induced by anticancer agents $(8,9)$.

In this study we described for the first time the isolation, characterization, the survival- and apoptosis-pathways of 
MaDe's active compound, GA, in different types of cancer cell lines from different organs. Our results suggest that GA isolated from $\mathrm{MaDe}$, as a natural compound, may provide the possibility of an application for cancer prevention and therapy.

\section{Materials and methods}

Plant materials. Phaleria macrocarpa (Scheff.) Boerl (Thymelaceae) or MaDe was purchased from the Research Institute for Industrial Plants at Manoko, Lembang, West Java, Indonesia. The plant species was identified by the laboratory of Plant Taxonomy staff at Herbarium Bogoriense, Bogor, Indonesia. A voucher of the specimen was deposited at the Herbarium of the Bandung Institute of Technology, Bandung, Indonesia.

Extraction and isolation. The fresh fruits of Phaleria macrocarpa (Scheff.) Boerl (8 kg) was extracted with $201 \mathrm{MeOH}$. The $\mathrm{MeOH}$ extract (128 g) was partitioned between EtOAc and water to afford an active EtOAc extract (4.2 g) and then was chromatographed on Silica G-60 ( $n$-hexane-EtOAc$\mathrm{MeOH}$ in $10 \%$ steps) to obtain two active fractions (60 and $65 \%$ EtOAc eluate). The active fractions were combined and then further chromatographed on ODS eluted with $\mathrm{H}_{2} \mathrm{O}$ $\mathrm{MeOH}$ (10\% steps) yielded three active fractions (10-30\% $\mathrm{MeOH}$ eluates). Further purification of active fractions on Silica G-60 with $n$-hexane-acetone (65:35) and continued with re-crystallization in $\mathrm{MeOH}$ yielded an active compound of GA 1 (248.6 mg).

Toxicity assay against brine shrimp. The eggs of brine shrimp, Artemia salina, were hatched in a beaker filled with artificial sea water according to the partially modified Meyer method (10). Into a sample tube, a certain amount of the test solutions to be tested was added. After removing the sample solvent, $2 \mathrm{ml}$ of sea water containing nauplii was poured into the sample tube. Twenty to thirty nauplii were treated at each dosage, and the nauplii which showed mortality were counted every hour for $24 \mathrm{~h}$ after initiating the administration.

Cell lines. Seven cancer cell lines (TE-2, human esophageal cancer, MKN-28, gastric cancer, HT-29 and Colo201, colon cancer, MCF-7, breast cancer, CaSki, cervix cancer and colon 26, mouse colon cancer) and one non-cancerous cell line (CHEK-1, immortalized human esophageal cell) were used. The cells were obtained from the American Tissue Culture Collection (ATCC, Rockville, MD, USA) except for TE-2 cell (provided by Dr T. Nishihira) (11) and CHEK-1 cell (provided by Dr H. Matsubara). CHEK-1 was established by transduction of human papillomavirus type $16 \mathrm{E} 6 /$ E7 into primary cultures of esophageal keratinocytes (12). The cell lines were cultured in RPMI-1640 medium (Sigma, St. Louis, MO, USA) supplemented with $10 \%$ fetal bovine serum (FBS) and antibiotics (100 $\mathrm{U} \mathrm{ml}^{-1}$ penicillin and $100 \mu \mathrm{g}$ $\mathrm{ml}^{-1}$ streptomycin).

Drug sensitivity assay. Cell proliferation analysis was performed on cells in the presence of increasing concentrations of GA by the tetrazolium assay using MTT as described previously (13). Briefly, cells $\left(2 \times 10^{4} /\right.$ well) were plated in 96-well plates, $50 \mu 1$ for each well. After the initial cell seeding, various concentrations of GA $(0.01-6.25 \mathrm{mg} / \mathrm{ml})$ were incubated for $24 \mathrm{~h}$. WST-8 assay (Dojindo Lab., Tokyo, Japan), $10 \mu \mathrm{l}$ of the cell counting solution was added to each well and incubated at $37^{\circ} \mathrm{C}$ for $3 \mathrm{~h}$. The formazan was dissolved in $100 \mu \mathrm{l} /$ well $1 \mathrm{~N} \mathrm{HCl}$. Cell proliferation rate was then determined by measuring the absorbance of the well at $450 \mathrm{~nm}$ with the reference wavelength at $650 \mathrm{~nm}$. Cell proliferation inhibition rate (CPI, \%) was calculated by the following formula:

$$
\text { (1- } \left.\frac{\text { Optical density of the treated cells }}{\text { Optical density of the control }}\right) \times 100
$$

The absorbance was read using a microtiter plate reader (Becton-Dickinson, Franklin Lakes, NJ, USA). Results were derived from triplicate experiments.

Microscopic examination. Cells were cultured and treated with GA as described above. Morphological apoptotic changes were examined at the time indicated and photographed using a regular phase-contrast microscope.

Cell extraction and Western blot analysis. The protein concentration was determined using a BCA Protein Assay Kit (Pierce, Rockford, USA). Protein $(40 \mu \mathrm{g})$ was run on $5-20 \%$ TrisTricine ReadyGel (Bio-Rad, Tokyo, Japan), electrotransferred to a hybond-enhanced chemiluminescence membrane (Amersham, Buckinghamshire, UK). The apoptosis-related protein was analyzed using a Bax, Bcl-2, Xiap, Apaf-1, caspase-3, -8, -9, and PARP (1:1000, Cell Signaling). The survival-related protein was analyzed using a p-Akt, p-mTOR and p-p70S6K (1:1000, Cell Signaling). The bands were detected using an enhanced chemiluminescence detection system (Amersham). B-actin (Sigma) served as control. Scanning densitometry was performed by using acquisition into Adobe Photoshop (Apple, Inc., Cupertino, CA) and analysis by the Quantity One (Bio-Rad).

Flow cytometric analysis. Cell sample preparation and propidium iodide (PI) staining was performed as described previously (13). At $\sim 80 \%$ confluent, the cells were treated with the $\mathrm{IC}_{50}$ and washed with fresh medium. Cell were harvested as control, 12 and $24 \mathrm{~h}$ for cell cycle distribution which was determined using FACScan Coulter EPICS XL Flow Cytometer (Coulter Corp., USA) with an argon laser set to excite at wavelength $488 \mathrm{~nm}$.

DNA fragmentation assay. Soluble DNA was extracted from floating and attached cells $0-24 \mathrm{~h}$ treatment with GA $\left(\mathrm{CPI}_{50}\right)$. Cultured cells were harvested, washed with cold phosphatebuffered saline (PBS) and pelleted by centrifugation at $300 \mathrm{~g}$, $10 \mathrm{~min}$ as describe previously (13). The DNA was extracted with phenol-chloroform and precipitated with $2 \mathrm{vol} / \mathrm{vol}$ of ethanol at $-20^{\circ} \mathrm{C}$ for $24 \mathrm{~h}$. The precipitated DNA was centrifuged at $13,000 \mathrm{~g}$ for $30 \mathrm{~min}$ at $4^{\circ} \mathrm{C}$ and allowed to air-dry. The DNA was then re-suspended in TE buffer (10 mM Tris at $\mathrm{pH} 7.5$ and $10 \mathrm{mM}$ EDTA) and quantified by absorbance 

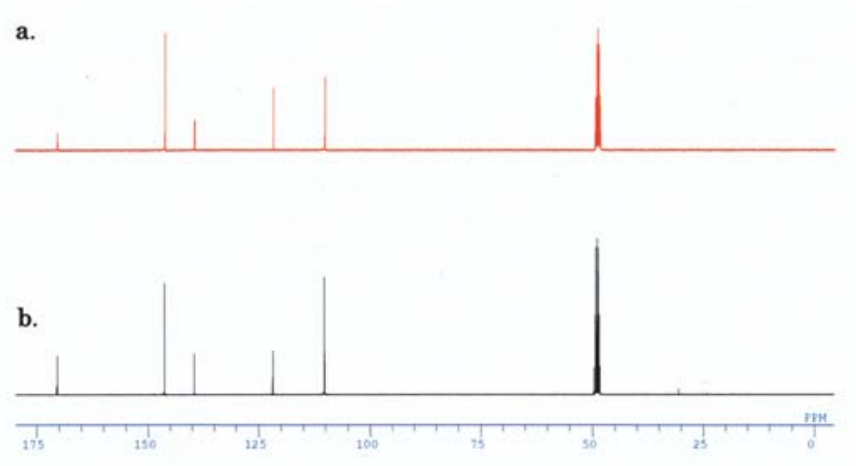

c.

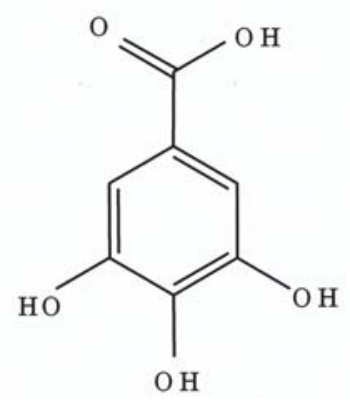

Figure 1. Column chromatography (NMR) on both normal- and reversedphase silica gel yielded a known compound of galllic acid, GA. (a) Red, GA which commercially available used as control; (b) Black, GA isolated from MaDe. (c) Chemical structure of gallic acid.

at $260 \mathrm{~nm}$ (Beckman DU 640, USA). DNA (10 $\mu \mathrm{g})$ was applied to $2 \%$ agarose gel, electrophoresed at $50 \mathrm{~V}$ for $45 \mathrm{~min}$ and the gels were stained with ethidium bromide.

Statistical analysis. Statistical analysis was performed using Stat View software (ver. 5.0, SAS Institute Inc., NC, USA). The statistical significance of differences was considered significant when $\mathrm{P}$-value was $<0.05$.

\section{Results}

Isolation of GA from MaDe and primary analysis of its cytotoxic activity. Melting points were determined on a FisherJohn melting-point apparatus and were uncorrected. UV spectra were obtained on a Shimadzu UV-1650PC instrument in $\mathrm{MeOH}$. IR spectra were measured on Perkin-Elmer Spectrum One FT-IR spectrometer. Mass spectra were recorded on a JMS AX-500. ${ }^{1} \mathrm{H}$ and ${ }^{13} \mathrm{C}$ NMR spectra were obtained with a JEOL JNM A-500 spectrometer. Chemical shifts are given on a $\delta$ (ppm) scale with TMS as an internal standard. Column chromatography separations were carried out on silica gel 60 (Merck; 70-200 and 230-400 mesh) and Chromatorex ODS (Fuji Silysia, Japan). TLC analysis was performed on pre-coated silica gel $60 \mathrm{~F}_{254}$ plates and RP-18 $\mathrm{F}_{254 \mathrm{~S}}$ (Merck; $0.2 \mathrm{~mm}$ ), spots being visualized by UV absorption at 254 and fluorescence at $365 \mathrm{~nm}$ or by spraying with $10 \% \mathrm{H}_{2} \mathrm{SO}_{4}$ in ethanol followed by heating. The GA (3,4,5-Trihydroxybenzoic acid), colorless noodles $(\mathrm{MeOH}) ; \mathrm{mp} 251-253^{\circ} \mathrm{C}$; UV $\lambda^{\mathrm{MeOH}_{\max }} \mathrm{nm}: 218,275 \mathrm{~nm}$; IR
$\mathrm{v}^{\mathrm{KBr}}{ }_{\max } \mathrm{cm}^{-1}: 3400,1715,1620,1100,737$; HREI-MS [found $m / z 171[\mathrm{M}+\mathrm{H}]$.

Bioactivity-guided purification of active constituents from a methanol extract of the fruits of Phaleria macrocarpa by silica gel chromatography using gradient elution with $n$-hexane-EtOAc-MeOH, followed by further column chromatography on both normal- and reversed-phase silica gel yielded a known compound of GA as shown in Fig. 1a and $b$. The GA (3,4,5-Trihydroxybenzoic acid) was isolated as crystal needles from methanol. The molecular formula of GA was identified as $\mathrm{C}_{7} \mathrm{H}_{6} \mathrm{O}_{5}$ by EIMS together with ${ }^{1} \mathrm{H}$ and ${ }^{13} \mathrm{C}$ NMR spectral and compared with the authentic compound as shown in Fig. 1c. The lethal dose $\left(\mathrm{LD}_{50}\right)$ of gallic acid was $5.8 \mathrm{ppm}$ evaluated for its activity in Artemia salina (data not shown).

Drug sensitivity assay. We evaluated the effect of GA on cell viability using the MTT assay. As shown in Fig. 2, treatment of non-cancerous and cancer cell lines with GA $(0.01-6.25 \mathrm{mg} / \mathrm{ml})$ resulted in the dose-dependent inhibition of cell growth when assessed $24 \mathrm{~h}$ post-treatment. The $\mathrm{CPI}_{50}$ values of isolation product were estimated to be $0.8,0.2,0.05,0.18,0.19,0.19$, 0.1 and $0.12 \mathrm{mg} / \mathrm{ml}$ for CHEK-1, TE-2, MKN-28, HT-29, Colo201, MCF-7, CaSki and colon26, respectively (Table I). We used TE-2 and CHEK-1 cells, since these cells were isolated from the same organ, esophagus, for further studies using Western blotting, flow cytometric and DNA fragmentation assays.

GA induces morphological changes in esophageal cancer cells. When human esophageal cancer TE-2 cells were treated with GA at $0.2 \mathrm{mg} / \mathrm{ml}$, clear morphological changes were observed $12 \mathrm{~h}$ after treatment but no such changes were seen in treated CHEK-1 cells (Fig. 3). Morphological changes in CHEK-1 were clearly observed $48 \mathrm{~h}$ after treatment with GA (data not shown). Treatment with GA induced a delayed occurrence of morphological changes in the CHEK-1 non-cancerous cells and it was obvious that GA treatment induced cell death in TE-2 cells.

GA induces caspase-cascade protein expression in esophageal cells. In cells undergoing apoptosis there is an activation of a family of proteases called caspases. Caspases are present in the inactive form and require cleavage peptides adjacent to an aspartic acid residue to activate the apoptosis process (14). Caspase signaling pathways consisting of a death receptordependent, extrinsic pathway and a death receptor-independent, intrinsic pathway were also examined in the cells treated with GA. We performed Western blotting on the members of caspases in the cell lysates obtained from GA-treated cells. As shown in Fig. 4a, the expressions of active caspase-8, -9, and -3 were found to be increased in TE-2 cells (poorly differentiated) in time-dependent manner. Along with this, the expression of Apaf-1 also increased and Xiap was found to be decreased (Fig. 4b). The cleaved form of caspase-cascade was detected as early as $12 \mathrm{~h}$ after treatment in TE- 2 cells. On the other hand, in CHEK-1 cells the cleaved form was detected slightly after $24 \mathrm{~h}$ (Fig. 4a). GA treatment activated the caspase-signaling pathway through both the extrinsic and intrinsic pathways. 

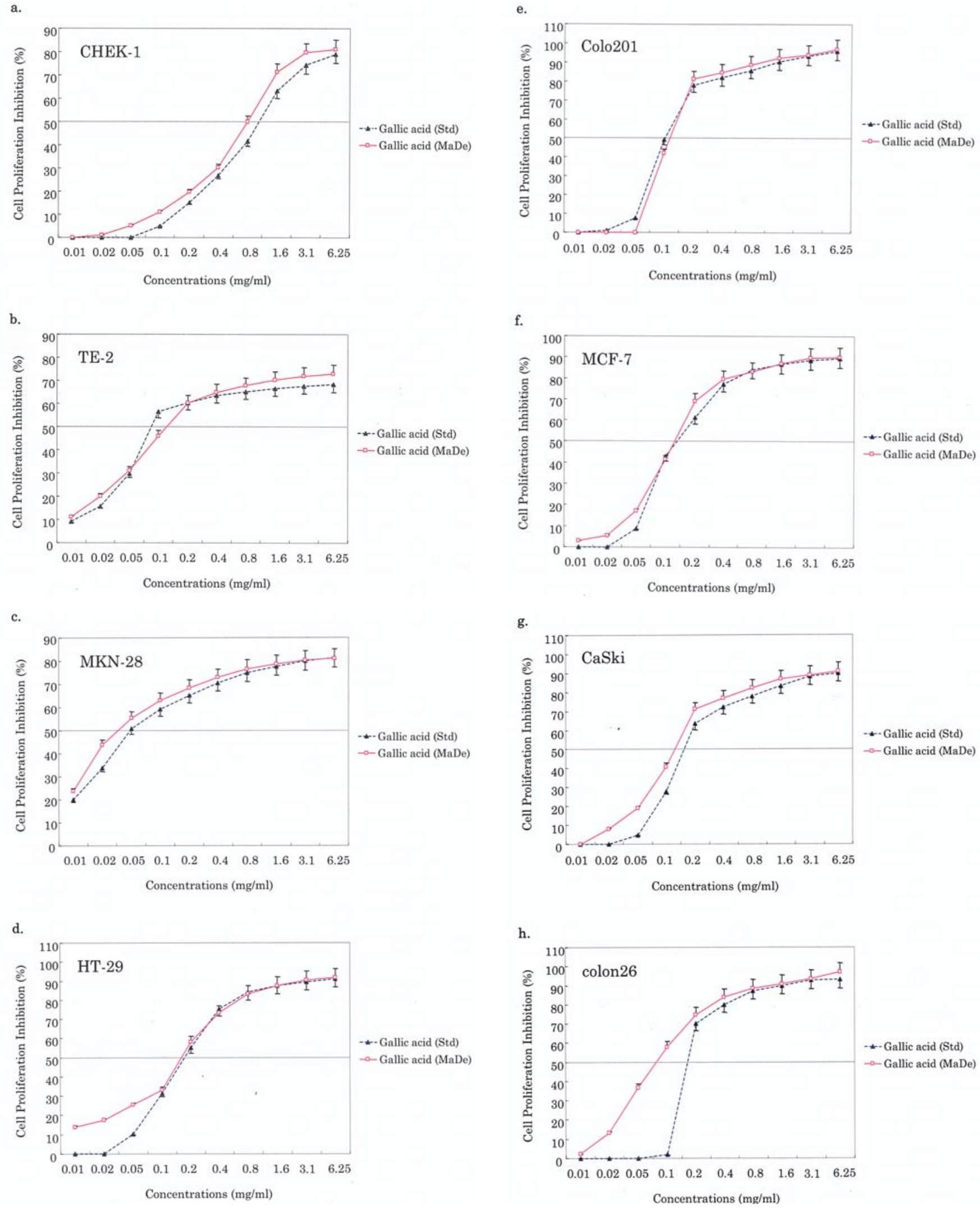

Figure 2. Effects of GA on viability of CHEK-1 (a), TE-2 (b), MKN-28 (c), HT-29 (d), Colo201 (e), MCF-7 (f), CaSki (g), and colon 26 cells (h). The cells were treated with various concentrations of GA $(0.01-6.25 \mathrm{mg} / \mathrm{ml})$ for $24 \mathrm{~h}$, and the viability was determined by the MTT assay. Std, standard; MaDe, Mahkota Dewa.

GA induces PARP cleavage and increases Bax protein expression. During apoptosis, the PARP protein is cleaved into an $89 \mathrm{kDa}$ C-terminal fragment that has reduced catalytic activity and a $24 \mathrm{kDa} \mathrm{N}$-terminal peptide that retains the DNA- binding domains. By Western blotting, TE-2 treated cells showed that the full-size PARP $(116 \mathrm{kDa})$ protein was cleaved to yield an $89-\mathrm{kDa}$ fragment $12 \mathrm{~h}$ post-treatment (Fig. $4 \mathrm{a}$ ). The expressions of the Bcl-2 family (pro- and anti-apoptosis) 
Table I. Minimum amounts of gallic acid giving $50 \%$ of cell proliferation inhibition of various cells. ${ }^{\mathrm{a}}$

\begin{tabular}{lcccccccc}
\hline & \multicolumn{7}{c}{ CPI $_{50}(\mathrm{mg} / \mathrm{ml})$} \\
\cline { 2 - 8 } Compounds & CHEK-1 & TE-2 & MKN-28 & HT-29 & Colo201 & MCF-7 & CaSki & Colon 26 \\
\hline Gallic acid (Std) & 1.14 & 0.3 & 0.09 & 0.24 & 0.18 & 0.24 & 0.28 & 0.26 \\
Gallic acid (MaDe) & 0.8 & 0.2 & 0.05 & 0.18 & 0.19 & 0.19 & 0.1 & 0.12 \\
\hline
\end{tabular}

${ }^{\mathrm{a}}$ MTT assay was conducted after 24-h incubation under the presence of each compound serially diluted from $6.25 \mathrm{mg} / \mathrm{ml}$ to $0.01 \mathrm{mg} / \mathrm{ml}$; $\mathrm{CPI}_{50}$, cell proliferation inhibition 50; MaDe, Mahkota Dewa.

a.

CHEK-1 0h

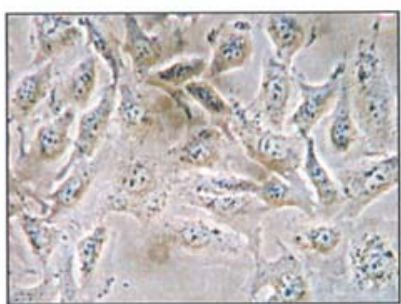

CHEK-1 GA $12 \mathrm{~h}$

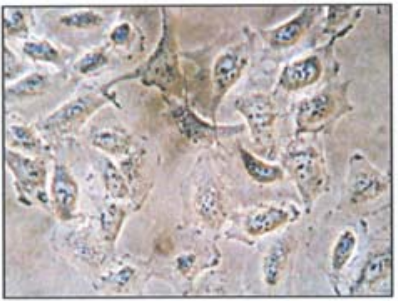

CHEK-1 GA 24h

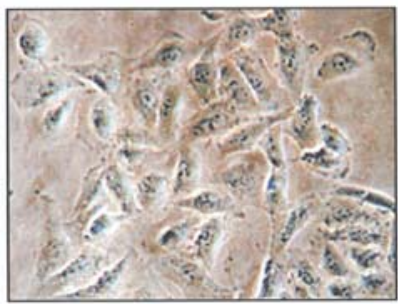

CHEK-1 GA $36 \mathrm{~h}$

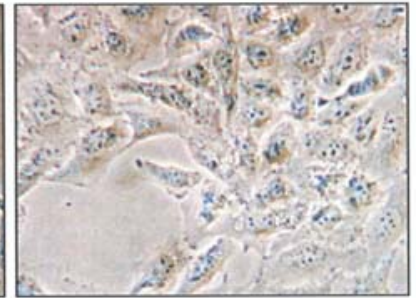

b.

TE-2 $0 \mathrm{~h}$

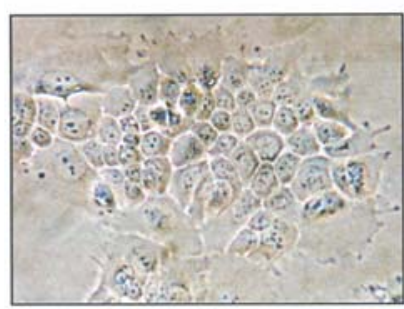

TE-2 GA $12 \mathrm{~h}$

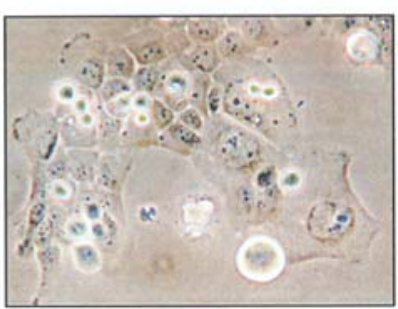

TE-2 GA 24h

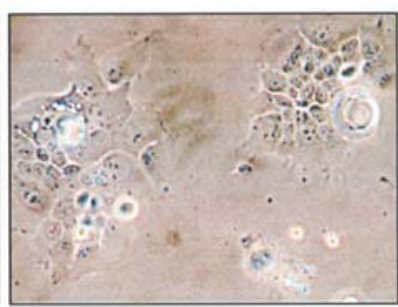

TE-2 GA 36h

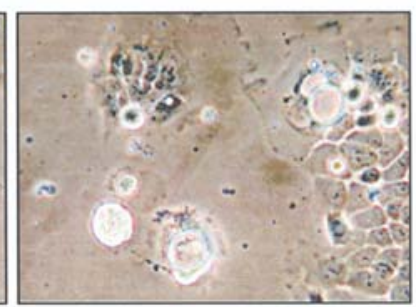

Figure 3. Representative photomicrographs of CHEK-1 cells (a) and TE-2 cells (b) treated with GA at each IC ${ }_{50}$ concentrations in time-dependent manner (magnification $\mathrm{x} 200$ ).

have been reported to play a role in the apoptotic response mediated by many agents (15). The effect of GA-treated cells on the protein level of the Bcl-2 family (such as Bax and Bcl-2) was then examined. Our results showed an increased in the protein expression of Bax (pro-apoptosis) in GA-treated cells (Fig. 4b). On the other hand, the protein expression of Bcl-2 (anti-apoptosis) was slightly decreased (Fig. 4b). Taken together, our results suggest that GA-induced apoptotic cell death was more rapid in esophageal cancer TE-2 cells, compared with the non-cancerous counterpart.

GA induces decreased expression of survival-related protein. One of the most important survival signaling pathways in a malignancy is mediated by Akt/mTOR (16). It was recently reported that these pathways play an important role in determining the chemo-sensitivity of many kinds of cells $(17,18)$. Our results from Western blot analysis clearly showed that treatment with GA reduced the expression of phosphorylation of Akt, mTOR and p70S6K in esophageal cancer TE-2 cells in a time-dependent manner (Fig. 4c). In contrast, GA did not reduce those survival-related protein expressions in noncancerous CHEK-1 cells (Fig. 4c).

Flow cytometric analysis. To investigate whether GA induces cell cycle changes and apoptosis in TE-2 cells, flow cytometric analysis of exponentially grown cells treated with $\mathrm{IC}_{50}$ of GA was performed. As shown in Fig. 5, GA increased the number of sub-G1 population (hypodiploid cells) $12 \mathrm{~h}$ after treatment $(14.8 \%)$, which referred to the cells that underwent apoptosis. After $24 \mathrm{~h}$, the number of sub-G1 cells was markedly increased and reached the peak level at $98.8 \%$. The kinetics of the cellcycle distribution of cells treated with GA is shown in Fig. 5. DNA fragmentation assay. A DNA fragmentation assay was performed to confirm the results of the MTT assays, Western blotting and flow cytometric analysis. GA treatment resulted in the degradation of chromosomal DNA into small internucleosomal fragments, as evidenced by the formation of 180-200 bp DNA ladders on $2 \%$ agarose gels. TE-2 cells 


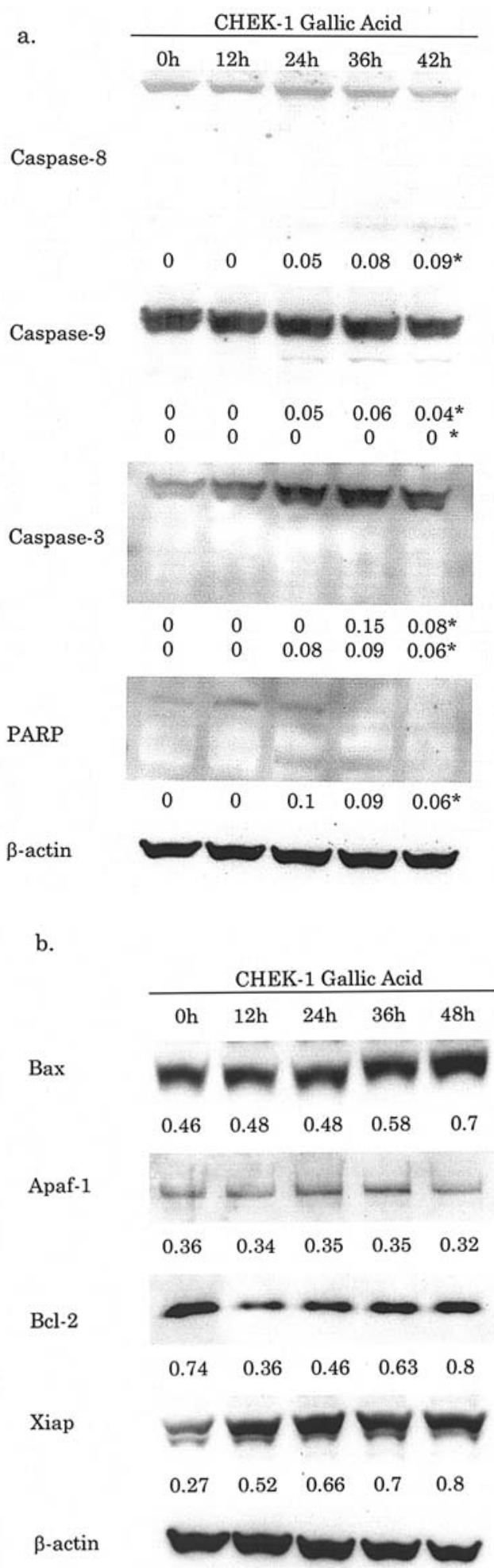

exhibited a clear and marked DNA ladder pattern at $12 \mathrm{~h}$ after GA exposure and increased over time as shown in Fig. 6. Herein we show that GA mediated the loss of cell viability in human esophageal cancer TE- 2 cells as a result of the induction of apoptosis and suppression of the survival pathways. The induction of apoptosis was evident when the morphological changes of TE-2 cells treated with GA resulted in morphological apoptotic changes after $12 \mathrm{~h}$. Consistent with the microscopic evaluation, Western blot analysis, flow
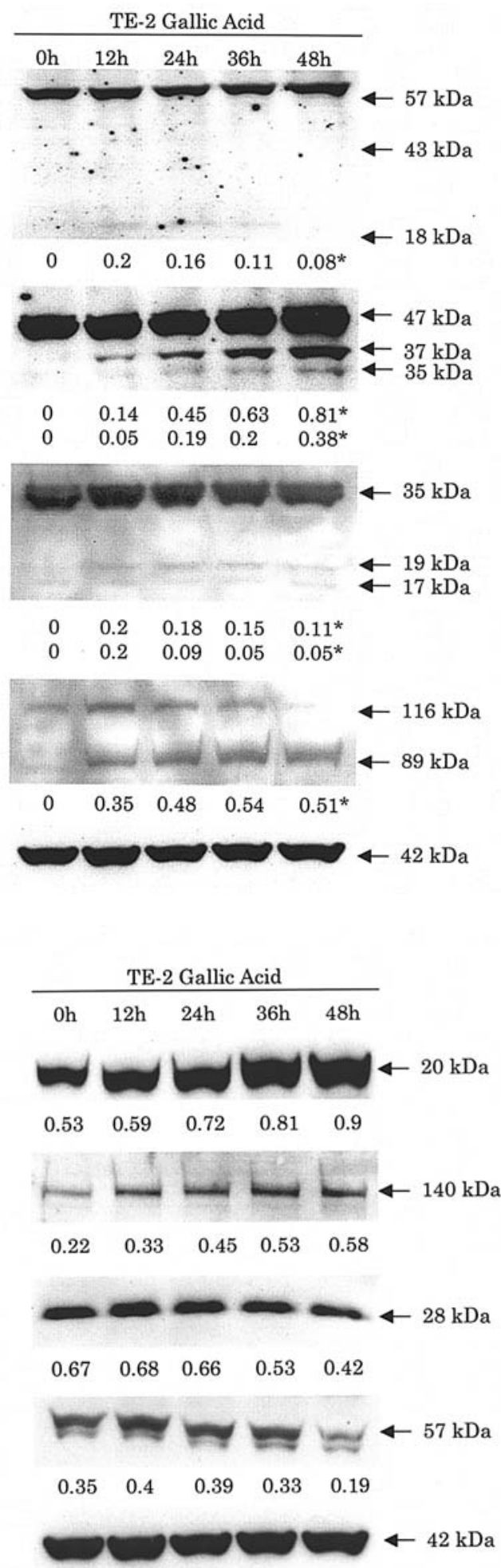

cytometric analysis and the DNA fragmentation revealed that treatment of TE- 2 cells with GA, activated the apoptosis machinery, resulting in apoptotic cell death (Figs. 3-6).

\section{Discussion}

In Indonesia, the use of medicinal plants and herbal therapy was practiced long before recorded history. Species of Phaleria macrocarpa, known as MaDe, have a long history 
c.

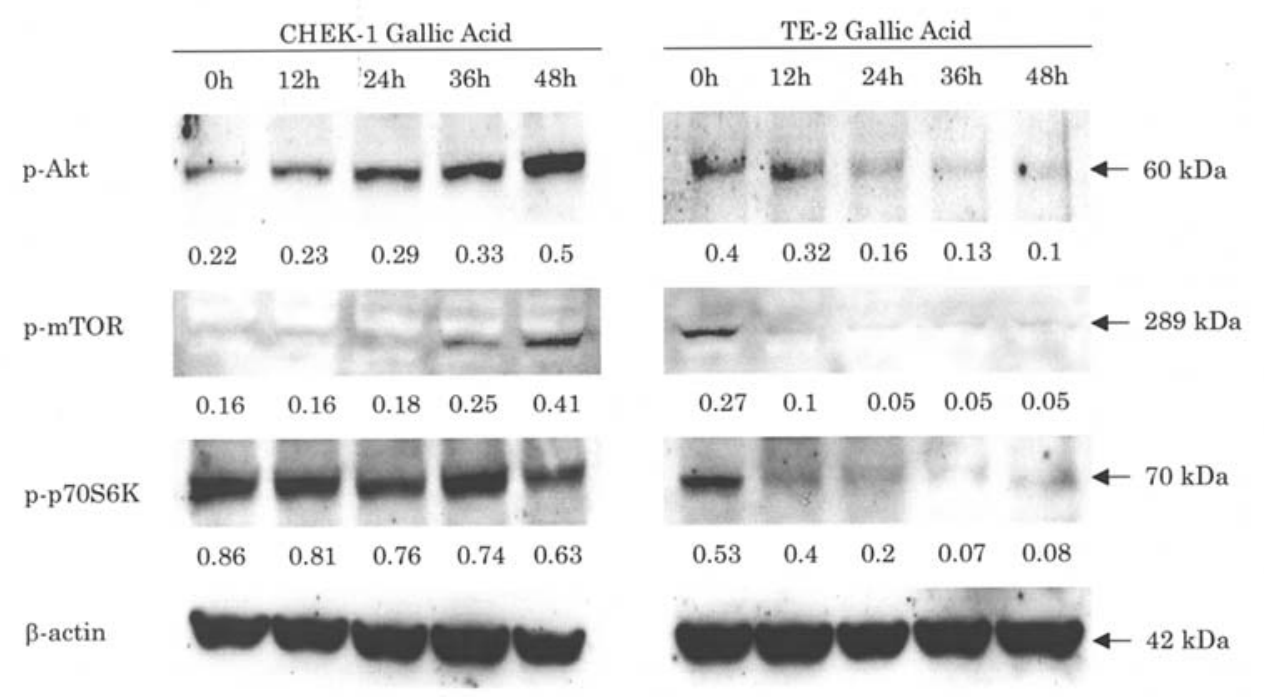

Figure 4. Western blot analysis of activation of the caspase-cascades and PARP in CHEK-1 and TE-2 cells (a). Values given below each picture represents the relative density of the bands normalized with $\beta$-actin. "Mark shown as cleaved form measured using densitometric analysis. The proteins expression of Bax, Bcl-2, Apaf-1, Xiap in CHEK-1 and TE-2 cells (b) treated with GA. The proteins expression of p-Akt, p-mTOR, p-p70S6K in CHEK-1 and TE-2 cells (c) treated with GA. Values given below each picture represents the relative density of the bands normalized with $B$-actin.

TE-2 GA $0 \mathrm{~h}$

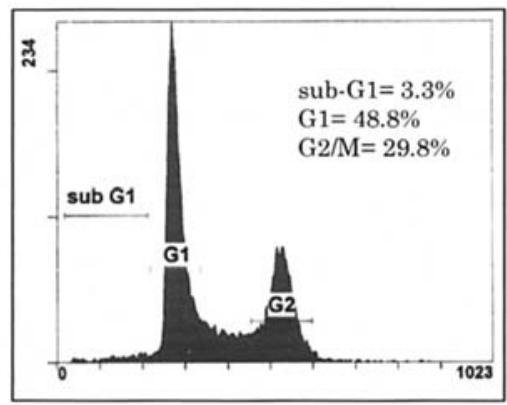

TE-2 GA $12 \mathrm{~h}$

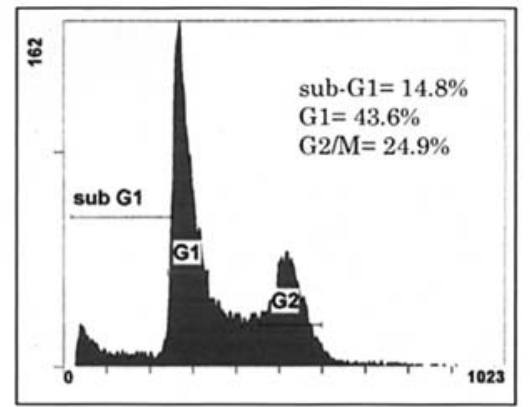

TE-2 GA $24 \mathrm{~h}$

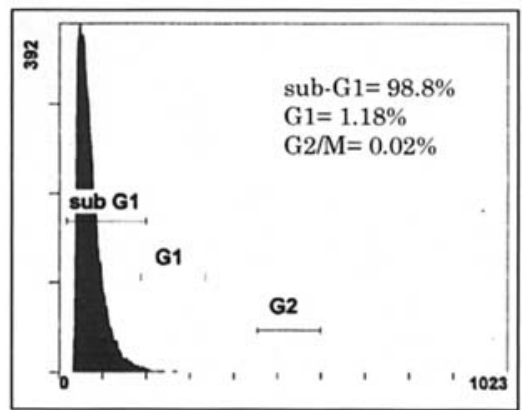

Figure 5. Cell cycle phase distribution of TE-2 cells treated with GA for the time indicated. DNA content in each cell cycle phase was determined by FACScan as described in Materials and methods.

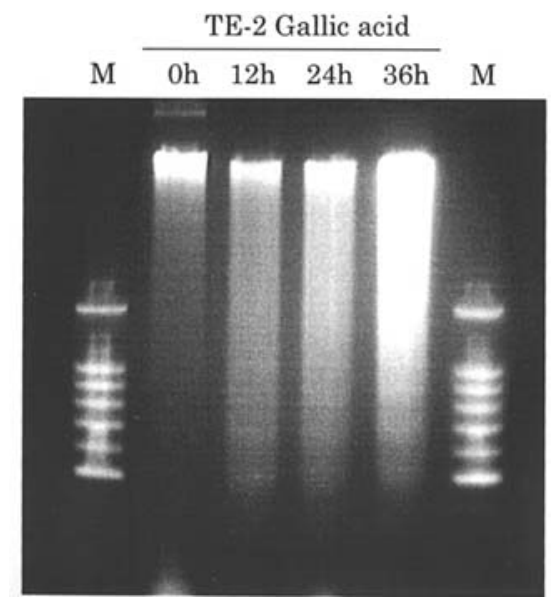

Figure 6. DNA fragmentation assay of TE-2 cells were treated with or without $\mathrm{GA}$ (by $\mathrm{IC}_{50}$ ) for various periods of time. After incubation, total DNA were isolated and subjected to electrophoresis on $2 \%$ agarose gel containing ethidium bromide as describes in Materials and methods. M, size marker of $100 \mathrm{bp}$ DNA ladder. of use in traditional medicine. MaDe has been used for the treatment of various diseases including empirical therapy for malignant diseases, such as cancer. It has been reported that the MaDe fruit is rich in alkaloid, saponin, and flavoid. MaDe leaves contain alkaloid, saponin, and polyphenol (19). All these compounds have been strongly suggested as anticancer agents $(20,21)$. There have been several studies supporting the anticancer potential of MaDe; however, scientific evidence concerning the mechanism of its active compound(s) is very limited.

Here we showed that GA isolated from MaDe inhibited cell growth of various cancer cell lines in a dose- and timedependent manner. We also provided evidence that the inhibitory effect of GA on carcinogenesis was mediated through the regulation of multiple signaling pathways. Our results suggest that GA activated cell death extrinsically along with mitochondrially intrinsic pathways and, thus, executed cell death as shown by PARP activation in cancer cells. This resulted in the inhibition of cancer development 
and its progression. Along with this, the Bcl-2 family (Bax and Bcl-2) imbalance was disturbed and the apoptosis machinery was activated.

Inhibition of survival signaling pathways and induction of apoptosis in cancer cells are the two major goals in cancer treatment. The hypothesis that the Akt/mTOR pathways might provide benefits for the prevention and treatment of cancer is based on many studies. Therefore, we analyzed the expression of these survival pathways along with apoptosis induced by GA. We found that activation of p70S6K and mTOR downstream of Akt was decreased after 12-h treatment with GA in esophageal cancer TE-2 cells. As expected, decreased expression of these survival signaling pathways somehow increased the effects of apoptosis-related proteins on the initiation of apoptosis machinery. In contrast, there was no reduction of the survival-related protein expression in non-cancerous CHEK-1 cells. It is tempting to speculate that GA might be less harmful to normal cells.

GA is known to induce cell death or cell cycle arrest in a variety of cancer cells in apparently different manner (22). Madlener et al found that GA induced cell cycle perturbation in the G1 phase (Madlener S et al, unpublished data). Meanwhile, Salucci et al showed that GA can interfere with the G2/M phase in colon adenocarcinoma cells (5). On the contrary, in our research, as well as in studies by Inoue et al (3) and Hsu et al (23) such phenomena were not found. Our results revealed that GA-induced apoptosis was not triggered at a specific phase of the cell cycle. GA did not affect the cell cycle profile; however, it increased the number of apoptotic cells (sub-G1 populations) in a time-dependent manner. This controversial result concerning the effect of GA on cell cycles possibly occurred for the following reasons: A) different cell types used, $\mathrm{B})$ various concentrations, and $\mathrm{C}$ ) the observation time of GA treatment differed in each study. Further study is needed to elucidate the role of GA in cell cycles which induce apoptosis.

Consistent with the MTT assay and Western blotting, in flow cytometric analysis TE-2 cells treated with GA demonstrated the highest sub-G1 population and cleared the appearance of DNA fragmentations at $12 \mathrm{~h}$ post treatment, which is known as a hallmark of apoptotic cell death. It has been suggested that GA induced apoptosis through reactive oxygen species (ROS) generation, $\mathrm{Ca}^{2+}$ influx and activation of calmodulin (3).

A successful anticancer compound should kill or incapacitate cancer cells without causing excessive damage to normal cells. Certain products from plants are known to induce apoptosis in cancer cells but not in normal cells $(24,25)$. Thus, it is important to screen apoptotic inducers from plants, either in the form of crude extracts or as active isolated components. In conclusion, a growing body of evidence has emerged, based on many studies, suggesting that products derived from plants are useful in the treatment as well as in the prevention of cancer. Understanding the exact mechanism of their actions may provide valuable information for their possible application in cancer therapy and prevention.

\section{Acknowledgements}

We thank Dr T. Nishihira (Tohoku University School of Medicine, Japan) for TE-2 cell line, Dr H. Matsubara
(Department of Academic Surgery, Chiba University, Japan) for CHEK-1 cell line. This work was supported by Grants-inAid from the Ministry of Education, Culture, Sports, Science and Technology, Japan for A.F., Yoneyama Rotary Foundation for L.S.F., in part from the 21st Century Center of Excellence (COE) Program, Japan.

\section{References}

1. Sporn MB and Suh N: Chemoprevention of cancer. Carcinogenesis 21: 525-530, 2000.

2. Sun J, Chu YF, Wu X and Liu RH: Antioxidant and antiproliferative activities of common fruits. J Agric Food Chem 50: 449-454, 2002.

3. Inoue M, Suzuki R, Koide T, Sakaguchi N, Ogihara Y and Yabu Y: Antioxidant, gallic acid, induces apoptosis in HL-60RG cells. Biochem Biophys Res Commun 204: 898-904, 1994.

4. Kawada M, Ohno Y, Ri Y, et al: Anti-tumor effect of gallic acid on LL-2 lung cancer cells transplanted in mice. Anticancer Drugs 12: 847-852, 2001

5. Salucci M, Stivala LA, Maiani G, Bugianesi R and Vannini V: Flavoids uptake and their effect on cell cycle of human colon adenocarcinoma cells (Caco2). Br J Cancer 86: 1645-1651, 2002.

6. Sohi KK, Mittal N, Hundal MK and Khanduja KL: Gallic acid, an antioxidant, exhibits anti apoptotic potential in normal human lymphocytes: a Bcl-2 independent mechanism. J Nutr Sci Vitaminol 49: 221-227, 2003.

7. Taraphdar AK, Roy M and Bhattacharya RK: Natural products as inducers of apoptosis: Implication for cancer therapy and prevention. Curr Sci 80: 1387-1396, 2001

8. Asnaghi L, Bruno P, Priulla M and Nicolin A: mTOR: the protein kinase switching between life and death. Pharmacol Res 50: 545-549, 2004.

9. Vignot S, Faivre S, Aguirre D and Raymond E: mTOR-targeted therapy of cancer with rapamycin derivatives. Ann Oncol 16: 525-537, 2005.

10. Meyer BN, Ferrigni NR, Putnam JE, Jacobsen LB, Nichols DE and McLaughlin JL: Brine shrimp: a convenient general bioassay for active plant constituents. J Med Plant Res 45: 31-34, 1982.

11. Nishihira T, Hashimoto Y, Katayama M, Mori S and Kuroki T: Molecular and cellular features of esophageal cancer cells. J Cancer Res Clin Oncol 119: 441-449, 1993.

12. Sashiyama H, Shino Y, Sakao S, et al: Alteration of integrin expression rates to malignant progression of human papillomavirus-immortalized esophageal keratinocytes. Cancer Lett 177: $21-28,2002$.

13. Faried A, Faried LS, Kimura H, et al: Differential sensitivity of paclitaxel-induced apoptosis in human esophageal squamous cell carcinoma cell lines. Cancer Chemother Pharmacol 57: 301-308, 2006.

14. Thornberry NA: The caspase family of cysteine proteases. $\mathrm{Br}$ Med Bull 53: 478-490, 1997.

15. Gupta S, Afaq F and Mukhtar H: Involvement of nuclear factorkappa B, Bax and Bcl-2 in induction of cell cycle arrest and apoptosis by apigenin in human prostate carcinoma cells. Oncogene 21: 3727-3738, 2002.

16. McCormick F: Cancer: survival pathways meet their end. Nature 428: 267-269, 2004

17. Nguyen DM, Chen GA, Reddy R, et al: Potentiation of paclitaxel cytotoxicity in lung and esophageal cancer cells by pharmacologic inhibition of the phosphoinositide 3-kinase/protein kinase B (Akt)-mediated signaling pathway. J Thorac Cardiovasc Surg 127: $365-375,2004$.

18. Faried LS, Faried A, Kanuma T, et al: Inhibition of the mammalian target of rapamycin (mTOR) by rapamycin increases chemosensitivity of CaSki cells to paclitaxel. Eur J Cancer 42: 934-947, 2006.

19. Gotama I.B.I, Sugiarto S, Nurhadi M, et al: Inventory of Indonesian medicinal plants. Research units and development, Ministry of Health (Jakarta) 5: 147-148, 1999.

20. Yoshida T, Hatano T and Ito H: Chemistry and function of vegetable polyphenols with high molecular weights. Biofactors 13: 121-125, 2000.

21. Tsuda H, Ohshima Y, Nomoto H, et al: Cancer prevention by natural compounds. Drug Metab Pharmacokinet 19: 245-263, 2004. 
22. Serrano A, Palacios C, Roy G, et al: Derivatives of gallic acid induces apoptosis in tumoral cell lines and inhibits lymphocyte proliferation. Arch Biochem Biophys 351: 49-54, 1998.

23. Hsu CL, Huang SL and Yen GC: Inhibitory effect of phenolic acids on the proliferation of 3T3-L1 preadipocytes in relation to their antioxidant activity. J Agric Food Chem 54: 4191-4197, 2006.
24. Hirano T, Abe K, Gotoh M and Oka K: Citrus flavone tangeretin inhibits leukaemic HL-60 cell growth partially through induction of apoptosis with less cytotoxicity on normal lymphocytes. Br J Cancer 72: 1380-1388, 1995.

25. Chiao C, Carothers AM, Grunberger D, Solomon G, Preston GA and Barrett JC: Apoptosis and altered redox state induced by caffeic acid phenethyl ester (CAPE) in transformed rat fibroblast cells. Cancer Res 55: 3576-3583, 1995. 